\title{
Impuestos moderados, según Ibn Jaldún
}

Eduardo Escartín González, Francisco Velasco Morente y Luis GonzálezAbril

\section{OpenEdition}

\section{Journals}

Edición electrónica

URL: http://journals.openedition.org/medievalista/768

DOI: 10.4000/medievalista.768

ISSN: 1646-740X

\section{Editor}

Instituto de Estudos Medievais - FCSH-UNL

\section{Edición impresa}

Fecha de publicación: 1 enero 2012

\section{Referencia electrónica}

Eduardo Escartín González, Francisco Velasco Morente y Luis González-Abril, « Impuestos

moderados, según Ibn Jaldún », Medievalista [En línea], 11 | 2012, Puesto en línea el 25 febrero 2014, consultado el 20 abril 2019. URL : http://journals.openedition.org/medievalista/768; DOI : 10.4000/ medievalista.768

\section{(C) IEM}


Título: Impuestos moderados, según Ibn Jaldún.

Autor(es): Eduardo Escartín González / Francisco Velasco Morente / Luis González-Abril Enquadramento Institucional: Grupo de Investigación SEJ-442 de la Universidad de Sevilla / Departamento de Economía Aplicada I de la Universidad de Sevilla / Departamento de Economía Aplicada I de la Universidad de Sevilla Contacto: escartin@us.es, Velasco@us.es, luisgon@us.es Fonte: Medievalista [Em linha]. №11, (Janeiro - Junho 2012). Dir. José Mattoso. Lisboa: IEM.

Disponível em: http://www2.fcsh.unl.pt/iem/medievalista/ ISSN: 1646-740X

\section{Resumo}

Ibn Jaldún foi um dos primeiros expoentes (século XIV) do liberalismo económico que teve uma concepção materialista da história. Assim se explica que mencione instituições do âmbito da economia e exponha o seu pensamento económico, que aqui mostrámos extraindo-o directamente do seu Muqaddimah e usando o método absolutista. Relacionámos algumas das suas ideias com outras similares doutras épocas e ressaltámos as que, ainda hoje, nos parecem úteis. Das suas considerações destacámos o desenvolvimento económico; a circulação monetária; a riqueza; a liberdade de comércio; e o preço. Ibn Jaldún readquire actualidade porque as suas considerações parecem descrever situações ainda vigentes no presente. Algumas destas propostas poderiam aplicar-se hoje para superar as crises económicas; mesmo não mencionando inovações tecnológicas, naturalmente inconcebíveis na sua época.

Palavras-chave: Idade Média, Islão, Pensamento económico, Liberalismo, Materialismo. 


\title{
Abstract
}

Ibn Khaldun was an early exponent (XIV century) of the economic liberalism and he had a materialistic conception of history; hence he refers to the institutions in the area of economy and presents his economic thought, which we make it known by employing the methodological absolutism and extracting it directly from his Muqaddimah. We relate some of his ideas with other similar exposed in different periods, and we emphasize those that are still useful today. From his considerations we highlight economic development, currency circulation, wealth, free trade, and price. Ibn Khaldun is taking on higher relevance for the reason that his considerations still seem to describe current situations and his proposals could be implemented today to overcome the economic crisis, even though he did not mention technological innovations that were unthinkable at his time.

Keywords: Middle Ages, Islam, Economic Thought, Liberalism, Materialism.

\section{Impuestos moderados, según Ibn Jaldún}

\author{
Eduardo Escartín González; Francisco Velasco Morente; \\ Luis González-Abril
}

\section{Introducción}

Abú Zayd Abd al-Rahmán ibn Muhammad Ibn Jaldún (Túnez 1332 - El Cairo 1406) fue un historiador tunecino descendiente de una aristocrática familia sevillana refugiada en el norte de África poco antes de la conquista cristiana de Sevilla. Como otros musulmanes cultísimos, siendo adolescente ya sabía de memoria el Corán bajo siete versiones llamadas las lecciones auténticas. Por involucrarse en intrigas políticas tuvo que emigrar, encontrando asilo en el Reino nazarí de Granada. Hacia 1363 fue 
embajador de este reino ante el rey de Castilla, Pedro I el Cruel, quien le ofreció la devolución de las tierras de sus antepasados (en el término del actual municipio de Dos Hermanas) con la condición de que residiera en Sevilla, lugar de la corte del rey castellano; aunque rechazó el ofrecimiento. Se trasladó al reino de Tremecén (en la actual Argelia), donde escribió su Kitab al-'ibar (Historia universal) antes de 1382. Esta historia está precedida por un extenso prólogo denominado Muqaddimah (Prolegómenos) que contiene su concepción de la historia, su pensamiento económico y una descripción general de la economía con referencia al papel del Estado y a numerosas instituciones económicas, como los precios, los impuestos y otras. En el año recién citado marchó a Egipto residiendo en el Cairo. Debido a su gran sabiduría y elocuencia fue elegido para desempeñar altos cargos relacionados con la judicatura, como cadí para los seguidores de la escuela malikí. En 1387 cumplió con la recomendada peregrinación a la Meca. En 1401 fue a Damasco cumpliendo una misión diplomática ante Tamerlán (autoproclamado heredero y continuador de Gengis Kan). Murió en el Cairo en 1406.

Sobre Ibn Jaldún hay mucho escrito, incluso en el aspecto económico, como el excelente trabajo de Estapé $^{1}$. Empero, nosotros deseamos abstraernos de cualquier estudio precedente para lograr una aportación personal sin influencias ajenas. Así, pues, seguidamente presentamos, en un enfoque novedoso, sus ideas económicas indagándolas directamente de su Muqaddimah e interpretándolas según el absolutismo metodológico de Blaug ${ }^{2}$, las comparamos con otras similares expuestas en distintas épocas y resaltamos los aspectos todavía útiles en la actualidad.

\section{Materialismo histórico}

Ibn Jaldún concibió materialistamente la evolución histórica, aunque de forma distinta a la de Marx $^{3}$, para quien una variación sustancial del sistema de producción de los bienes

\footnotetext{
${ }^{1}$ Fabián ESTAPÉRODRÍGUEZ:Ibn Jaldún: un economista del siglo XIV, en Economía y Economistas Españoles, Tomo 2, Barcelona, 1999, pp. 75-97.

${ }^{2}$ Mark BLAUG: Teoría económica en retrospección; Madrid, 1988, pp. 25 y ss.

${ }^{3}$ Karl Heinrich MARXy Friedrich ENGELS:La Ideología Alemana, Montevideo, 1968, pp. 19-27.
} 
económicos (o sea, la alteración del modo en que las personas se ganan la vida)modifica las formas de relacionarse las personas, tanto en sus relaciones de producción como en sus relaciones de intercambio y también en sus relaciones de distribución de las rentas generadas, de forma que las transformaciones de la estructura económica causaun cambioen la superestructura ideológica y jurídica (es decir, en la mentalidad de la gente).Ibn Jaldún ${ }^{4}$ (Libro II, Cap. I) dice que la gente está en sociedad para ayudarse a ganarse la vida y que la manera en que cada pueblo se procura su subsistencia marca la diferencia existente entre sus instituciones. Además, éstas van cambiando con la evolución de la sociedad. Por otra parte, se aprecia que para Ibn Jaldún ${ }^{5}$ (Libro II, Cap. IV) la forma de ganarse la vida condiciona las costumbres y la conducta de la gente; idea magistralmente resumida por nuestro insigne Cervantes $^{6}\left(2^{a}\right.$ Parte, Cap. IV): «los oficios mudan las costumbres». Ibn Jaldún ${ }^{7}$ (Libro III, Cap. XIII), describe cómo los imperios pasan por etapas: surgen, se desarrollan, decaen y sucumben, de modo que las condiciones económicas que predominan en cada una de ellas preparan el cambio para la siguiente.

Por lo general, los pueblos nómadas que desprecian la muerte, por estar forjados en los rigores de la naturaleza y llevar un género de vida austero y recio, conquistan un imperio con elevado grado de desarrollo cultural y económico, según comenta Ibn Jaldún $^{8}$ (Libro II, Cap. XVI y Cap. XXI). Para éste ${ }^{9}$ (Libro III, Cap. XI y Cap. XV), una nación conquistadora adopta pronto la vida más refinada del país dominado, pasando a gozar de la abundancia y de los elevados niveles de comodidad «y empieza bien pronto a advertir cuán es lo superfluo indispensable». Los vencedores «se dejan arrastrar por toda clase de deleites y refinamientos, despliegan un gran esmero en la mesa, sus vestidos, sus muebles y vajillas». Continúa narrando Ibn Jaldún ${ }^{10}$ (Libro III, Cap. XIII) cómo se va introduciendo el lujo y la molicie en su nuevo modo de vivir: Los individuos, mientras los núcleos tribales participen conjuntamente del poder, todavía estarán dispuestos a luchar y perder la vida por alcanzar honor, conservar el imperio y

\footnotetext{
${ }^{4}$ Ben JALDÚN: Introducción a la historia universal (Al-Muqaddimah), México, 1997, p. 263.

${ }^{5}$ B. JALDÚN,ibídem, p. 268.

${ }^{6}$ Miguel de CERVANTES: El Ingenioso Hidalgo Don Quijote de la Mancha, Madrid, 1966, p. 506

${ }^{7}$ B. JALDÚN,ibídem, pp. 345-347.

${ }^{8}$ B. JALDÚN,ibídem, pp. 294 y 305.

${ }^{9}$ B. JALDÚN,ibídem, pp. 343 y 351.

${ }^{10}$ B. JALDÚN,ibídem, pp. 345-346.
} 
sus posesiones. Sin embargo, el poder acaba siendo ejercido por una única persona que, para mantenerse en él, reprime el ardor guerrero, la bizarría y la cohesión tribal del resto de los conquistadores. Éstos empiezan a ser súbditos con mentalidad de tales, es decir de personas sometidas a la autoridad de otra. Temiendo que sus propiedades sean confiscadas si atentan contra el soberano, prefieren llevar una vida cómoda y lujosa sin crearse problemas. Paulatinamente se va introduciendo entre los miembros poderosos de la sociedad un consumo fastuoso que contrasta con la miseria de los pobres oprimidos por onerosas exacciones para que los ricos prosigan con sus ostentosos despilfarros. El nivel de vida se eleva y se precisa subir el salario de los funcionarios, sirvientes y soldados. Luego, en el devenir histórico, los gastos del Estado superarán a los ingresos (pese a la creación de nuevos impuestos y al aumento de sus tasas) ya que la tributación alcanza un límite recaudatorio por provocar el desinterés económico; a partir de ese momento incluso los ingresos fiscales decrecen. Concluye Ibn Jaldún ${ }^{11}$ (Lib. III, Cap. XXXVIII y Cap. XXXIX): «El producto de los impuestos disminuye y, por consecuencia necesaria, mengua la renta del Estado». Los necesarios recortes presupuestarios afectan al ejército cuyos efectivos disminuyen y, por tanto, también merma la capacidad defensiva del imperio. Mas el afán de opulencia y los desmedidos gastos no disminuyen; al contrario, siguen aumentando y a la par se debilita el ejército, cuyas tropas valoran más el buen vivir que el buen morir con gloria. Tal imperio, en su evolución histórica, ya está en condiciones óptimas de perecer si una nueva nación emergente decide atacarlo y conquistarlo.

Estas descripciones de Ibn Jaldún parecen ser intemporales, porque servirían perfectamente para describir situaciones actuales y de otras épocas.

Los antropólogos del materialismo cultural, escuela encabezada por Harris ${ }^{12}$, estudian en nuestros días los aspectos económicos en que se desenvuelven los pueblos para explicar las diferencias habidas en sus respectivas sociedades, que, en el fondo es lo que decía Ibn Jaldún.

\footnotetext{
${ }^{11}$ B. JALDÚN,ibídem, pp. 505 y 506.

${ }^{12}$ Marvin HARRIS:Antropología cultural, Madrid, 1998.
} 


\section{Desarrollo económico}

Nuestro autor complementa su concepción materialista con una teoría sobre la prosperidad de la nación. Ésta, según Ibn Jaldún ${ }^{13}$ (Lib. III, Cap. XLII y Cap. XXIV), se basa en fomentar el bienestar del pueblo, que depende: de unas remuneraciones altas; de los grandes gastos del sultán y su gobierno que son el motor de la economía; y de las relaciones económicas entre el soberano y los súbditos. Si éstas son buenas, es decir si el monarca trata a su pueblo justa y benefactoramente, se propiciará el incremento de la productividad en provecho del dirigente y sus dependientes; mas si la gobernación es tiránica y opresiva la economía se desincentiva arruinando a toda la nación. En concreto dice Ibn Jaldún ${ }^{14}$ (Lib. III, Cap. L): «Bajo una administración justa y benévola, los corazones se abren a la esperanza y se entregan con entusiasmo a todas las actividades que favorecen al desarrollo social». Ideas similares ya habían sido expuestas a finales de siglo XI, o principios de XII, por el musulmán išbīlī (sevillano) Ibn Abdún, para quien en las sociedades cobra un sentido muy especial las relaciones relativas a la producción, que se establecen de forma ineludible en las comunidades humanas. La relevancia de las relaciones sociales de producción estriba en que mientras unas favorecen la integración de los miembros de la sociedad y el aumento de la productividad, otras provocan su desintegración y la disminución de la productividad. Sobre esto veamos cómo se explicaba Ibn Abdún ${ }^{15}$ en el primer epígrafe de su opúsculo (de tan sólo 230 epígrafes, que, en lo sucesivo, se designarán con el símbolo §):

La justicia, en efecto, ha sido siempre apreciada; amado, el bien; deseable, la rectitud; rechazable, la contradicción; detestable, el mal. La verdad siempre se ha tenido por brillante y la falsedad por torcida. La incuria y el descuido han provocado siempre, por el contrario, la pobreza y el hambre; han dado origen a todos los daños y crisis; han determinado el aumento de los tumultos y desórdenes; han favorecido la ruina de un país y obligado a sus habitantes a expatriarse. Sobre todo, si, al mismo tiempo, aumenta la ilegalidad; si el pueblo se hace sensible a las seducciones del demonio, y si el soberano, dejándose

\footnotetext{
${ }^{13}$ B. JALDÚN,ibídem, pp. 515 y 376.

${ }^{14}$ B. JALDÚN,ibídem, p. 540.

${ }^{15}$ B. ABDÚN:Sevilla a comienzos del siglo XII. El tratado de Ibn ${ }^{\mathrm{c}}$ Abdún, Madrid, 1948, $\$ 1$.
} 
arrastrar por la satisfacción de sus veleidades, se hace menos asequible a sus vasallos, les cierra sus puertas y multiplica entre ellos y su persona el número de sus chambelanes, porque entonces reduce a los buenos al silencio y presta oídos a los maldicientes desocupados, con lo cual sufren daño, tanto la religión como la custodia del bienestar de los musulmanes.

Obsérvese que tales juicios, tanto los de Ibn Jaldún como los de Ibn Abdún, hoy serían perfectamente asumibles, así como adaptables al presente los siguientes:

Según Ibn Jaldún ${ }^{16}$ (Lib. III, Cap. XXIV y Cap. XXXVIII) si el sultán basa su señorío en el beneficio de sus vasallos y en un gravamen moderado y justo (o sea, imponiendo sólo los tributos legales, los estipulados en el Corán, cuyas tasas son de poca monta, según comenta Ibn Jaldún), entonces el pueblo seguirá al monarca haciendo suya su causa. El pueblo trabajará con ánimo sabiendo que el producto de su laboriosidad redunda en su propio interés y que sus emolumentos no disminuyen; la producción aumentará a la par que el número de contribuyentes y los ingresos del Estado. La riqueza de éste se basa en la de sus ciudadanos, pues Ibn Jaldún ${ }^{17}$ (Lib. IV, Cap. XVII) nos hace reparar en que «cuanto más ricos y numerosos son los súbditos tanto más dinero posee el gobierno». Este principio es similar al expresado por Salomón (Prov. 14, 28): «In the multitude of people is the king's honour: but in the want of people is the destruction of the prince. $=$ En un pueblo numeroso estriba la dignidad del rey, y en la escasez del pueblo se encuentra la destrucción del príncipe». Ibn Jaldún ${ }^{18}$ (Lib. III, Cap. XLIII) afirma que «el progreso social y la actividad de su desarrollo dependen del trabajo y de la aplicación de los hombres a los medios del lucro y el bienestar». Así pues, los tributos bajos incentivan la actividad económica aumentando los ingresos fiscales del sultán; el monarca será poderoso y podrá mantener un potente ejército que defienda a la nación y a sus habitantes de la rapiña de sus enemigos. Como dice Ibn Jaldún $^{19}$ (Lib. III, Cap. XLIII):

La religión sólo se sostiene por el rey; el poderío del rey consiste en sus tropas;

\footnotetext{
${ }^{16}$ B. JALDÚN,ibídem, pp. 376 y 504.

${ }^{17}$ B. JALDÚN,ibídem, p. 656.

${ }^{18}$ B. JALDÚN,ibídem, p. 516.

${ }^{19}$ B. JALDÚN,ibídem, p. 517.
} 
el mantenimiento de las tropas requiere dinero; el único medio para obtener dinero es el desarrollo económico y social; ningún desarrollo se logra sin una justa administración; la justicia es una balanza que el Altísimo ha instalado en medio de sus criaturas y a la cual ha designado un administrador, que es el rey.

Por contra, si las relaciones del sultán con los súbditos son malas, porque éste es violento, pierde la rectitud moral y atropella a las personas apoderándose de sus bienes, los súbditos se desalientan, se muestran reticentes y faltos de diligencia para cumplir los dictados del soberano; incluso llegan a abandonarle en las batallas, desean su muerte y a veces consiguen asesinarlo. El pueblo, viendo que el fruto de su trabajo acaba en manos del señor, pierde la esperanza de obtener beneficios y deja de trabajar, tanto más cuanto mayor sea el grado de las vejaciones padecidas. Así, la injusticia y las malas relaciones sociales conducen a mermar la productividad y, aun aumentando los impuestos, los ingresos del monarca bajarán y con ello los recursos para el desarrollo colectivo.

Por estos motivos, Ibn Jaldún ${ }^{20}$ (Lib. III, Cap. XLIII) considera que:

La gente se dispersa por distintos horizontes para buscar en otros países los medios de existencia que ya no encuentra en el suyo; la población del reino disminuye, los poblados quedan sin habitantes, las ciudades caen en ruina. Tal estado de cosas trastorna la organización del gobierno, quien, siendo "la forma" de la prosperidad pública, debe necesariamente descomponerse cuando la "materia" de esa prosperidad se altera.

Así pues, la injusticia y la opresión destruyen el progreso, porque descorazonan a la población y terminan por hacerla emigrar [o sumergiendo su actividad económica en la clandestinidad]. Lo cual vemos que sigue ocurriendo en nuestros días y en el pasado también sucedió manifiestamente en España, hasta el punto de ser recogida esa clase de expatriación de la población debido a la penuria económica por Ibn Abdún, según él comentaba en su $§ 1$, recién transcrito, y también, por el Consejo de Castilla ${ }^{21}$ ante la

\footnotetext{
${ }^{20}$ B. JALDÚN,ibídem, p. 516.

${ }^{21}$ CONSEJO SUPREMO DE CASTILLA: Consulta del Consejo Supremo de Castilla, en Obras del Licenciado Pedro Fernández Navarrete, en Biblioteca de Autores Españoles, Tomo 25, Madrid, 1853, p. 450 .
} 
Consulta del rey Felipe III en 1618 sobre las causas de los males que aquejaban al reino, en cuyo informe dice que lo primero es «la despoblación [...] y la causa de ella nace de las demasiadas cargas y tributos [por lo que los vasallos] es fuerza que hayan de desamparar sus hijos y mujeres y sus casas, por no morir de hambre en ellas, e irse a las tierras donde esperan poderse sustentar»; a lo cual, añade Navarrete (Disc. XVIII) ${ }^{22}$ a principios del siglo XVII:

cuando los labradores ven que el rédito de las heredades no es suficiente a la paga de la renta que ha de dar al señor, y a la de los censos que sobre ella tiene tomados, y a los pechos y tributos que le están impuestos, con facilidad se resuelve a desampararlas, buscando el sustento, o en limosnas o en mudarse a otras tierras, donde las cargas sean más ligeras

Resumiendo estas ideas, Ibn Jaldún ${ }^{23}$ (Lib. III, Cap. XXXVIII) dice «que el medio más eficaz para la prosperidad de un país estriba en aminorar en cuanto posible las cargas que el Estado impone a los trabajadores; de esta suerte se entregarían con ánimo y gusto al trabajo, confiados en recoger la utilidad correspondiente». Esta preocupación por rebajar las tasas de los impuestos igualmente fue una propuesta reiterada de Ibn Abdún $^{24}$. Mucho después, en la España de principios del siglo XIX, ideas similares sobre la reducción de impuestos para fomentar la actividad económica serían expuestas por el gaditano José Manuel de Vadillo ${ }^{25}$ y luego llevadas a la práctica por el ministro de Hacienda español Laureano Figuerola mediante su arancel de 1869 (de la múltiple literatura sobre ello, puede verse en Pardos $\operatorname{Martínez}^{26}$ y en Costas $^{27}$ ). En el siglo XX, las ideas de Ibn Jaldún a este respecto fueron plasmadas en un gráfico por Arthur B. Laffer: nos referimos a la curva de Laffer en forma de U invertida.

\footnotetext{
${ }^{22}$ Pedro FERNÁNDEZ NAVARRETE: Conservación de Monarquías, en Biblioteca de Autores Españoles, Tomo 25, Madrid, 1853, p. 482.

${ }^{23}$ B. JALDÚN,ibídem, p. 505.

${ }^{24}$ B. ABDÚN, ibídem, $\$ 61,62,65,66,69$ y 100.

${ }^{25}$ José Manuel de VADILLO: Discursos Económicos-Políticos y Sumario de la España Económica de los siglos XVI y XVII, corregidos y aumentados, Cádiz, 1844, pp. 18, 21, 51 nota al pie, 115 y 307.

${ }^{26}$ Eva PARDOS MARTÍNEZ:La incidencia de la protección arancelaria en los mercados españoles. Madrid, 1998, p. 18.

${ }^{27}$ Antón COSTAS COMESAÑA: Industrialización y cuestión arancelaria en España. Reflexiones en torno al liberalismo de Laureano Figuerola, en Economía y economistas españoles, Tomo 4, Barcelona, 2000, pp. 469-470.
} 
En otro orden de consideraciones, Ibn Jaldún ${ }^{28}$ (Lib. IV, Cap. XVII) añade que «la dinastía y el reino son la "forma" de la nación y del desarrollo social, y su "materia" es todo lo relacionado con el Estado, como súbditos, ciudades, etc.»Vemos que Ibn Jaldún utiliza términos de la teoría hilemorfista de Aristóteles $^{29}$ (Lib. $7^{\circ}$, Cap. III), a quien conoce a través de la divulgación de sus obras hecha por Averroes, autores ambos que cita en el Lib. II, Cap. XIII ${ }^{30}$. Más tarde, a mediados del siglo XVIII, también adoptaría este modo de expresión Cantillón ${ }^{31}$, para quien la tierra es la materia de la que proviene toda la riqueza y el trabajo es la forma que adopta al producirla.

Por otra parte, esta teoría del progreso económico de Ibn Jaldún, basada en el fomento por parte del soberano del gasto público y de unas relaciones de producción justas para que los particulares se dediquen a sus actividades económicas con alta productividad y beneficio público, contrasta con la que, excluyendo la participación activa del poder político, Smith ${ }^{32}$ expondría, a finales del siglo XVIII, mediante su famosa metáfora de la mano invisible:

Cada individuo [...] sólo piensa en su ganancia propia; pero [...] es conducido por una mano invisible a promover un fin que no entraba en sus intenciones. Mas no implica mal alguno para la sociedad que tal fin no entre a formar parte de sus propósitos, pues al perseguir su propio interés, promueve el de la sociedad de una manera más efectiva que si esto entrara en sus designios.

Pero Smith no tuvo en cuenta que si alguien en la búsqueda de su ingreso máximo perjudica a otro (por ejemplo, arruinando al vecino con procedimientos ilegales, ya que Smith, pese a haber sido moralista, ni siquiera puso limitaciones morales o legales a su enunciado) obviamente es difícil que así se alcance esa pretendida mejoría del ingreso global de la sociedad y es seguro que, al resultar alguien perjudicado (por ejemplo, las personas arrojadas al paro por la actuación del que buscaba su máximo ingreso en beneficio propio), el interés de la sociedad en su conjunto no resulta beneficiado. Es

\footnotetext{
${ }^{28}$ B. JALDÚN,ibídem, p. 656.

${ }^{29}$ ARISTÓTELES: Metafísica, Madrid, 1994, p. 284.

${ }^{30}$ B. JALDÚN,ibídem, p. 287.

${ }^{31}$ Richard CANTILLON: Ensayo sobre la naturaleza del comercio en general, México, 1996, pp. 13 y 29.

${ }^{32}$ Adam SMITH: Investigación sobre la naturaleza y causas de la riqueza de las naciones, México, 1994, p. 402.
} 
evidente que si se pretende alcanzar el bien común de la sociedad lo que hay que buscar es éste sin que nadie salga dañado. Está claro que la gente debe resultar favorecida, cuanta más mejor, pero eso no quiere decir que en el camino de beneficiar a alguien haya que ir dejando un reguero de damnificados; a éstos hay que resarcirles sus pérdidas o propiciarles el encuentro de nuevas ocupaciones. También olvida Smith que en una sociedad los resultados económicos no dependen exclusivamente del provecho individual sino de las relaciones de producción, de suerte que si estas son excelentes los trabajadores ponen más empeño en sus tareas y su productividad aumenta; en cambio, si las relaciones de producción se deterioran, aumenta la conflictividad laboral, decae la motivación del trabajador y la productividad disminuye. Como dice Ibn Jaldún ${ }^{33} \ll \mathrm{El}$ sultán [...] guía a los súbditos» y su «liberalidad es una manifestación de la bondad, un aspecto de la diligencia que el sultán muestra por asegurarles los medios de vivir». Así pues, las buenas relaciones productivas y las ganancias particulares de los individuos en general deben ser fomentadas por el poder político; y este principio sigue vigente en nuestros días.

Puesto que Ibn Jaldún insiste en recomendar unos impuestos moderados para favorecer la prosperidad de la nación, tal como hoy algunos economistas proponen, en el Anexo resumimos nuestra interpretación sobre los impuestos legales en el islam clásico, que basamos principalmente en la reforma fiscal del califa (717-720) Omar II y difundida por $\mathrm{Gibb}^{34}$.

\section{Circulación del dinero}

Ibn Jaldún, al igual que Cantillón ${ }^{35}$, captó nítidamente que la circulación es lo esencial del dinero; de ahí que concibiera su flujo circular y su efecto multiplicador debido a la interdependencia de las actividades económicas. En la opinión de nuestro autor el dinero es un instrumento que ha sido instituido para circular continuamente sin ser

\footnotetext{
${ }^{33}$ B. JALDÚN,ibídem, p. 376.

${ }^{34}$ HamiltonAlexanderRosskeen GIBB:Fiscal Rescript of 'Umar II, en Arabica II, Leiden, 1955, pp. 1-17.

${ }^{35}$ R. CANTILLON, ibidem, pp. 82 y ss.
} 
retenido e ir creando riqueza y valor añadido al pasar de mano en mano. Esta idea igualmente fue aducida a principios del siglo XVII por Moncada al proponer que la actividad productiva y el comercio fueran realizados por nacionales en vez de por extranjeros (Lib. IV, Cap. IV) ${ }^{36}$. En concreto dice Ibn Jaldún ${ }^{37}$ (Lib. III, Cap. XLII): «el dinero no se ha hecho sino para estar pasando del sultán a sus súbditos y de los súbditos al sultán; si este lo retiene en sus arcas, los súbditos carecerán de ese dinero». Comenta Ibn Jaldún ${ }^{38}$ (Lib. III, Cap. XLVII) que el dinero en manos de la gente estimula la demanda que al aumentarse las fuentes de ingresos para los productores, facilita la multiplicación de los bienes y las riquezas. Ibn Jaldún ${ }^{39}$ (Lib. III, Cap. XLII y Cap. LI) se manifiesta en contra del atesoramiento de los ingresos fiscales, porque si ese dinero no regresara al pueblo en forma de erogaciones del sultán y del gobierno, las gentes no podrían sostener su nivel de vida y tendrían que disminuir sus gastos; las compras de estas gentes contribuyen al florecimiento del comercio y los mercados decaerían si ellas mermaran. Ibn Jaldún ${ }^{40}$ (Lib. III, Cap. XLII) considera los egresos del erario público tan importantes que dice: «El gobierno y el sultán constituyen el mercado principal de la nación, mercado del que procede toda la materia de la prosperidad pública». Así pues, continua diciendo Ibn Jaldún $^{41}$ (Lib. IV, Cap. XVII) «el dinero que el sultán derrama a raudales es cual un río que hace verdecer a sus contornos, fertiliza el suelo cercano y extiende su influjo bienhechor hasta puntos lejanos donde predomina la sequedad».

$\mathrm{Al}$ aumento de la prosperidad de la nación contribuye el flujo circular del dinero, que, según describe Ibn Jaldún ${ }^{42}$ (Lib. IV, Cap. XVII) es recogido por el monarca de los contribuyentes, luego pasa a los funcionarios y de estos a otros habitantes, de modo que se multiplican los medios para asentarse sobre una base sólida la práctica de las artes en todas sus ramas. Sobre esto Ibn Jaldún ${ }^{43}$ (ibídem) concluye:

El dinero que proviene de las contribuciones retorna al pueblo; la riqueza de la

\footnotetext{
${ }^{36}$ Sancho de MONCADA:Restauración Política de España, Madrid, 1974, pp. 162-163.

${ }^{37}$ B. JALDÚN,ibídem, p. 515.

${ }^{38}$ B. JALDÚN,ibídem, pp. 532 y 653-656.

${ }^{39}$ B. JALDÚN,ibídem, pp. 515 y 547.

${ }^{40}$ B. JALDÚN,ibídem, p. 515.

${ }^{41}$ B. JALDÚN,ibídem, p. 654.

${ }^{42}$ B. JALDÚN,ibídem, p. 653.

${ }^{43}$ B. JALDÚN,ibídem, p. 656.
} 
población deriva ordinariamente de los mercados y del comercio; las dádivas y las fortunas que el sultán vierte sobre algunos habitantes de la ciudad se derraman entre los demás y vuelven luego al soberano para ser distribuidas de nuevo. Los impuestos y las contribuciones territoriales (jar//.) se llevan el dinero del público; pero el sultán, al desembolsarlo, se lo devuelve. La riqueza del gobierno significa la de los súbditos, y cuanto más ricos sean los súbditos y numerosos, tanto más dinero posee el gobierno, pues todo eso depende del desarrollo social y de su magnitud.

En el caso del islam andalusí, García de Cortázar ${ }^{44}$ corrobora este hecho, al señalar que, debido a la enorme burocracia y a las dimensiones del ejército, el Estado «resultó ser el primer consumidor de al-Andalus y el principal creador de puestos de trabajo».

En esta línea de pensamiento continúa explicando Ibn Jaldún ${ }^{45}$ (Lib. III, Cap. XLII) lo que sucedería en caso contrario, si escaseara el dinero a causa de la restricción de los gastos. Entonces los mercados languidecerían y los negocios no rendirían beneficios. Por ello se resentiría el erario al mermar la recaudación fiscal, puesto que los impuestos y todas las fuentes de las rentas públicas se nutren del incremento del dinero, de su inversión, del comercio, de la actividad económica y «de los esfuerzos de los que trabajan con el aliciente de ganar y medrar». Como se ve su idea es similar a la difundida a principios del siglo XX por Keynes ${ }^{46}$, que fundamenta en última instancia tanto el crecimiento económico como la recesión en el efecto multiplicador del gasto.

\footnotetext{
${ }^{44}$ José Ángel GARCÍA de CORTÁZAR: La época medieval, en Historia de España Alfaguara, Tomo II, Madrid, 1977, p. 83.

${ }^{45}$ B. JALDÚN,ibídem, p. 515.

${ }^{46}$ John Maynard KEYNES, yHubert HENDERSON, ¿Puede hacerlo Lloyd George? Examen de la promesa, en Ensayos de Persuasión, Vol. I, Barcelona, 1997, pp. 96-133 y John Maynard KEYNES, Medios para la prosperidad, en Ensayos de Persuasión, Vol. II, Barcelona 1997, pp. 337-366.
} 


\section{Riqueza, propiedad privada y comercio}

Para Ibn Jaldún ${ }^{47}$ (Lib. V, Cap. I) «adquisición» es lo que los hombres consiguen gracias a sus esfuerzos y capacidad. Una parte de las adquisiciones constituye la riqueza que es el conjunto de cosas o bienes que obtienen los hombres por encima de lo que consumen en cantidad suficiente para atender a sus necesidades; es decir, la riqueza proviene del ahorro. Las riquezas que cada hombre posee se pueden emplear para adquirir otros bienes, pero a esta adquisición no se le puede dar el nombre de «beneficio» si la posesión de esos bienes no sirve para mejorar su vida y para atender a sus necesidades. Según comenta Ibn Jaldún ${ }^{48}$, algunos moralistas no consideran que sea beneficio lo que se ha alcanzado de forma ilegal o con violencia (o sea, causando perjuicio a alguien). Por otra parte, aunque todos los hombres desean lograr cosas, «ningún individuo puede pretender lo que otro ha obtenido, a menos que le diera algún objeto a cambio» ${ }^{49}$. De estas ideas se desprende que Ibn Jaldún ve como lo más natural la propiedad privada y el intercambio, siendo éste el medio de completar la satisfacción de las necesidades que no se cubren directamente con el trabajo personal. La asunción de la propiedad privada por los musulmanes está perfectamente de acuerdo con las estipulaciones del Corán ${ }^{50}$, donde se prescribe que: «Dios ha declarado lícita la venta».

Entre las adquisiciones para ganarse la vida, Ibn Jaldún ${ }^{51}$ considera (Lib. V, Cap. II) que hay actividades económicas naturales como la agricultura, la artesanía (o trabajo manual que comprende diversas artes y profesiones) y el comercio. La agricultura precede a las demás y «es el medio más antiguo y apropiado naturalmente para proporcionarse la subsistencia». Luego viene la artesanía, que se desarrolla en las urbes. En tercer lugar se encuentra el comercio, cuya actividad consiste en ingeniárselas para obtener una ganancia o beneficio mediante la diferencia entre el precio de venta y el de compra. Ibn Jaldún $^{52}$ añade (Lib. V, Cap. IX) que un modo de lograr ese beneficio es comprar la mercancía y almacenarla hasta que suba su precio en el mercado; otra consiste en transportar las mercancías desde su origen a otro sitio donde tengan mayor demanda y,

\footnotetext{
${ }^{47}$ B. JALDÚN,ibídem, p. 674.

${ }^{48}$ B. JALDÚN,ibídem, p. 674.

${ }^{49}$ B. JALDÚN,ibídem, p. 673.

${ }^{50}$ Corán, II, 276.

${ }^{51}$ B. JALDÚN,ibidem, pp. 676-677.

${ }^{52}$ B. JALDÚN,ibidem, p. 696.
} 
por tanto, mayor valor. En resumen, la naturaleza del comercio, en sus palabras, es «comprar a bajo precio y vender caro» ${ }^{53}$.

Estas «formas naturales» de ganarse la vida de Ibn Jaldún se parecen a las concepciones aristotélicas de adquisición natural y antinatural, pero con un notable cambio de enfoque, puesto que para Aristóteles ${ }^{54}$ la acumulación de riquezas mediante el uso del dinero (el comercio crematístico) era una forma antinatural. También, el procedimiento de forzar la obtención del beneficio comprando y almacenando las mercancías recuerda la descripción del monopolio efectuada por Aristóteles ${ }^{55}$. Por otra parte, al definir la naturaleza del comercio, Ibn Jaldún expresa nítidamente el principio de las ventajas absolutas (comprar donde hay baratura para vender donde esté caro) que también asumiría Smith $^{56}$, aunque este principio es muy antiguo pues ya habían reparado en él los clásicos griegos como Jenofonte ${ }^{57}$ y Aristóteles $^{58}$.

El comercio de larga distancia es muy remunerador puesto que los altos precios de venta obtenidos en países lejanos, carentes de ciertas mercancías, compensan con creces el «riesgo»y los elevados costes del transporte que presentan las rutas al «país de los negros»o «desde nuestro país [Ifriqiya] a Oriente», en expresiones del autor ${ }^{59}$ (Lib. V, Cap. X). En cambio, el comercio local proporciona beneficios mucho más reducidos. También opina Ibn Jaldún ${ }^{60}$ (Lib. V, Cap. X) que para la obtención de beneficios conviene elegir una mercancía que tenga una gran demanda, por ser necesaria para mucha gente, y que no sea cara, sino de calidad mediana, ya que los productos muy costosos sólo son asequibles para los ricos y no ofrecen tantas posibilidades de obtener ganancias.

\footnotetext{
${ }^{53}$ B. JALDÚN,ibídem, p. 696.

${ }^{54}$ ARISTÖTELES: La Política, Barcelona, 1967, pp.19-23 (Lib.1º, Cap.III,12-23).

${ }^{55}$ ARISTÖTELES, ibidem, p.25 (Lib. $1^{\circ}$, Cap.IV, 5-7).

${ }^{56}$ A. SMITH, ibidem, p. 329.

${ }^{57}$ JENOFONTE:Económico, Madrid, 1967, p. 428 (Cap. XX, 27 y 28).

${ }^{58}$ ARISTÖTELES, ibidem, p.20 (Lib. $1^{\circ}$, Cap.III, 15).

${ }^{59}$ B. JALDÚN,ibidem, p. 697.

${ }^{60}$ B. JALDÚN,ibidem, p. 697.
} 


\section{Libertad de comercio}

Aunque el desarrollo económico tiene que estar promovido por el Estado, Ibn Jaldún ${ }^{61}$ (Lib. III, Cap. XL) piensa que el soberano no debe participar activamente en la producción, porque tal ámbito pertenece a la esfera privada. De ahí que conciba la libertad de empresa y de comercio. Esta idea proviene de siglos atrás, pues ya había sido emitida por el emperador bizantino Teófilo, según comenta Montesquieu ${ }^{62}$ a propósito de un barco que traía mercancías a la emperatriz: «Soy emperador y me conviertes en patrón de galera. Si nosotros ejercemos su oficio, ¿cómo podrán ganarse la vida las pobres gentes?»; A esto Montesquieu apostilla que el emperador «podía haber añadido: ¿Quién podrá frenarnos si hacemos monopolio?»

Las fuentes típicas del erario del sultán son los impuestos y las rentas de sus propiedades (explotaciones agrícolas y empresas comerciales). Pero ante la insuficiencia de los ingresos, pese al aumento de la presión fiscal, el soberano no debe intensificar la explotación de sus propiedades ni crear más entidades comerciales. La participación directa del sultán en las actividades productivas es considerada por Ibn Jaldún ${ }^{63}$ (Lib. III, Cap. XL)perjudicial para la economía por tres razones:

$1^{\mathrm{a}}$, porque los agricultores y los comerciantes no pueden competir contra la riqueza y poder económico del sultán.

$2^{\mathrm{a}}$, porque el monarca puede apropiarse productos y mercancías por la fuerza (o sea, tiene poder para confiscar), o pagando un precio irrisorio, ya que nadie osa rechistar sus decisiones.

Y $3^{\mathrm{a}}$, porque el soberano puede imponer coactivamente los precios o la adquisición de sus productos, alterando en su favor el libre funcionamiento de los mercados.

\footnotetext{
${ }^{61}$ B. JALDÚN,ibidem, pp. 507-509.

${ }^{62}$ Charles-Louis de Secondat, barón de MONTESQUIEU: El Príncipe no debe Comerciar, Cap. XIX, Lib. XX Del Espíritu de las Leyes; Madrid, 1995.

${ }^{63}$ B. JALDÚN,ibidem, pp. 508-508.
} 
Adviértase que estas tres rúbricas, si se sustituye sultán (o sea, el Estado) por monopolio o monopsonio, se pueden aplicar a situaciones actuales. Tras este inciso prosigamos con Ibn Jaldún.

La intervención directa del soberano en la economía causa la ruina de muchos agricultores y comerciantes que, al no disponer de rentas para pagar los impuestos, acaba por arruinar al estado. La conclusión a la que llega Ibn Jaldún ${ }^{64}$ (Lib. III, Cap. XXXVIII) es que la prosperidad del soberano debe fundamentarse en la riqueza de sus súbditos sometidos sólo a los impuestos legales (el diezmo de caridad, el impuesto territorial y la capitación que únicamente pagan los judíos y cristianos) y mediante tasas impositivas reducidas. De esta suerte, los súbditos podrán prosperar en sus actividades económicas y sufragar la tributación necesaria para sostener al estado. Como se ve, Ibn Jaldún opina que un exiguo porcentaje sobre muchas partidas acaba sumando mucho más que otro alto sobre partidas cada vez más mermadas a medida que el pueblo se va empobreciendo. Esta apreciación, aplicada al hidrópico fisco español, fue señalada en el siglo XIX por Vadillo ${ }^{65}$ : «En 1566 se doblaron los derechos de almojarifazgo ó aduanas por la regla de que el guarismo 6 es más alto que el 3, aunque la suma de muchos de estos ascienda á infinitamente más que la de pocos de aquellos.» $\mathrm{Y}$ otro tanto de esto mismo podría volver a ocurrir en la España de hoy con presupuestos públicos muy deficitarios y aumento de la presión fiscal.

Pese a su concepción de liberalismo económico, Ibn Jaldún ${ }^{66}$ (Lib. V, Cap. XI) se muestra contrario al acaparamiento de los granos y productos indispensables para la vida de los hombres. En contra del acaparamiento de cereales, y en evitación del incremento de los precios por parte de los tratantes que pretendían monopolizar la venta de estos artículos, ya se había pronunciado Ibn Abdún $^{67}$ :

No se venda más de un cahíz de trigo cada vez a quien se sepa que es un acaparador, porque estos individuos se conciertan con los tratantes en un precio

\footnotetext{
${ }^{64}$ B. JALDÚN,ibídem, pp. 504-505.

${ }^{65}$ José Manuel de VADILLO: Discursos Económicos-Políticos y Sumario de la España Económica de los siglos XVI y XVII, corregidos y aumentados, Cádiz, 1844, p. 307.

${ }^{66}$ B. JALDÚN,ibídem, p. 699.

${ }^{67}$ B. ABDÚN, ibídem, $§ 104$.
} 
y luego se vuelven a sus casas, sin presenciar las operaciones de medición ni nada más, y es el tratante el que mide y le envía de una vez toda la cantidad, que ninguna otra persona puede comprar. Así sube el precio del trigo, pues, como no llega al mercado y se vende de golpe, se produce la natural alza de los precios y costos, con perjuicio de los musulmanes. [...] Se prohibirá a los tratantes que vendan a un acaparador una cantidad superior a la necesaria para el consumo anual de su familia, y vigílese que se haga así, porque de otro modo se produce el alza de los precios.

Compárese esto último con la breve recomendación, a mediados del siglo XVI, de Ortiz $^{68}$ sobre el acaparamiento: «Que ninguno pueda comprar más mercaderías de las que gastare en su trato e oficio».

Por otra parte, Ibn Jaldún opina ${ }^{69}$ (Lib. V, Cap. XII) que la subsistencia y el bienestar general de la mayoría de la población depende de precios bajos de los cereales, de modo que las necesidades de alimentación de la gente deben prevalecer sobre los intereses particulares de los comerciantes. Esto lo considera una excepción al caso general, puesto que él piensa ${ }^{70}$ (Lib. V, Cap. XII) que los precios deben ser moderadamente elevados, ya que los bajos precios hacen menguar todas las ramas de la producción, tanto en la agricultura como en la artesanía, porque no permiten cubrir los costes. La tendencia es que cuando las personas no obtienen algo de ganancia abandonan la actividad que desempeñan; por eso aconseja que las retribuciones no disminuyan (Lib III, Cap. XLII) ${ }^{71}$. Pese a su sensatez, este consejo, orientado a sostener la demanda, se olvida hoy, de forma que se retrasa la recuperación económica, al no mantenerse el poder adquisitivo por el recorte retributivo y el ahorro forzoso causado por la inflación que ambos menoscaban las posibilidades económicas de quienes los padecen.

\footnotetext{
${ }^{68}$ Luis ORTIZ: Memorial del contador Luis Ortiz a Felipe II, p. 69.

${ }^{69}$ B. JALDÚN,ibídem, p. 701.

${ }^{70}$ B. JALDÚN,ibídem, p. 700.

${ }^{71}$ B. JALDÚN,ibídem, p. 515.
} 


\section{Teoría del precio}

Ibn Jaldún ${ }^{72}$ (Lib. V, Cap. I) fundamenta el precio de los productos en el trabajo, ya que como él dice: «todos los bienes y riquezas requieren el trabajo del hombre. [...] La cría de animales, el cultivo de plantas y la explotación de minerales no puede obtenerse sin el trabajo del hombre; pues sin el trabajo, esas empresas no rendirían provecho alguno, ni se llevarían a cabo».Pero esta concepción está matizada con otras circunstancias que afectan al precio. Una de ellas es la escasez del producto (Lib. V, Cap. X) ${ }^{73}$ : «cuando los artículos son raros y de difícil obtención, suben naturalmente de precio». Por el contrario (Lib. IV, Cap. XII $)^{74}$, cuando hay abundancia, por ejemplo de granos alimenticios, de suerte que se supera la exigencia de la población, el precio baja en el mercado. Otra es la demanda (Lib. IV, Cap. XII $)^{75}$, de modo que si hay muchos solicitantes de un producto su cantidad puede convertirse en insuficiente para atender a todos y debido a la porfía de los más ricos para conseguirlo su precio sube. Este escueto argumento anticipa al más amplio de Malthus, en su opúsculo de 1800: An Investigation of the Cause of the Present High Price of Provisions, para explicar la formación del precio mediante la demanda efectiva, según transcripción de Keynes ${ }^{76}$ :

Supongamos una mercancía muy solicitada por cincuenta personas, de la cual, por algún fallo de la producción, sólo hay suficiente para abastecer a cuarenta. Si quien ocupa el cuadragésimo lugar, partiendo de arriba, dispone de dos chelines para gastar en esta mercancía y los treinta y nueve por encima de él tienen más, en diversas proporciones, y los diez bajo él todos menos, el efectivo precio de este artículo, según los genuinos principios del comercio, será de dos chelines [...]. Supongamos ahora que alguien da a los diez pobres que quedaron excluidos un chelín a cada uno. Los cincuenta pueden ahora ofrecer dos chelines, que es el precio que antes se pedía. De acuerdo con todos los verdaderos principios del comercio justo, esta mercancía debe subir inmediatamente. Si no, me preguntaría: ¿en razón de qué principio se ha rechazado a diez de los cincuenta

\footnotetext{
${ }^{72}$ B. JALDÚN,ibídem, p. 674.

${ }^{73}$ B. JALDÚN,ibídem, p. 697.

${ }^{74}$ B. JALDÚN,ibídem, p. 643.

${ }^{75}$ B. JALDÚN,ibídem, pp. 643-644.

${ }^{76}$ John Maynard KEYNES:"Robert Malthus (1766-1835): The First of the Cambridge Economists", en Essays and Sketches in Biography, pp. 11-38, New York, 1956, p. 25.
} 
que eran igualmente capaces de ofrecer los dos chelines? Porque, según el supuesto, siguen sin haber más que para cuarenta. Los dos chelines de un pobre son tan buenos como los dos chelines de un rico; y si actuamos para impedir que la mercancía suba hasta quedar fuera del alcance de los diez más pobres, quienesquiera que sean, tendremos que echar a suertes, hacer una lotería o luchar para determinar quiénes serán excluidos. Se saldría de mi presente propósito discutir si uno de estos métodos sería preferible para la distribución de las mercancías de un país, a la sórdida distinción del dinero; pero lo cierto es que, según las costumbres de todas las naciones ilustradas y civilizadas, y según todo principio del trato comercial, debe dejarse que el precio suba hasta el punto en que la adquisición se encuentre fuera del alcance de diez de las cincuenta personas.

Prosiguiendo ahora con la disertación de Ibn Jaldún (Lib. IV, Cap. XII) ${ }^{77}$, si la demanda es exigua, debido al «corto número de los habitantes y a sus raquíticos medios, los artículos son muy poco buscados y se venden bien baratos». Como se observa su inicial teoría del valor-trabajo se complementa con una escueta (pero moderna) teoría del precio a través de la oferta y la demanda fundada en un elemento objetivo (la escasez o abundancia relativas que conforma la oferta) y en otro subjetivo (la mayor o menor consideración hacia los productos que conforma la demanda).

\section{Colofón}

Ibn Jaldún es racionalista y procura no basar sus análisis socioeconómicos en la religión, pero la menciona a menudo y no puede evitar ajustar la actividad económica a los dictados del Corán, e igualmente sucede con el otro autor islámico aquí contemplado: Ibn Abdún. Observamos que en el Medioevo hubo, tanto en el orbe cristiano como en el islámico, una intensa penetración de la religión en la vida social y económica, como las consideraciones sobre la justicia en las relaciones productivas, los tributos y el precio justos. Todo ello apenas está distanciado de las apreciaciones de los

\footnotetext{
${ }^{77}$ B. JALDÚN,ibídem, p. 644.
} 
escolásticos cristianos pues ambos procuraban el ajuste de las conductas a sus respectivas teologías islámica y cristiana. Se trata de sistemas económicos incrustados, embedded en terminología del economista y antropólogo austriaco Karl Polanyi (según Godelier ${ }^{78}$ ), en otras estructuras sociales distintas de las económicas, como, en el caso de las sociedades islámicas medievales, la religiosa, que pretendía impregnar y dominar todas las áreas sociales. De esta forma, las condiciones de la regulación interna de la economía en general y de los mercados en particular no estaban verdaderamente en el propio sistema económico, sino en otras estructuras sociales, como la religiosa.

Además, Ibn Jaldún adopta una posición muy crítica y moralista al comentar los usos de los comerciantes (que recuerda nuevamente Ibn Abdún $^{79}$ y asimismo a Smith ${ }^{80}$ ). Según Ibn Jaldún ${ }^{81}$ (Lib. V, Cap. II), ellos suelen emplear artilugios para lograr la diferencia entre precio de venta y de compra con que obtener su ganancia. Algunas de esas artimañas, aun no siendo, en principio, ilegales, se basan en la astucia, la habilidad, el regateo y el engaño, cualidades morales de los comerciantes, que, para Ibn Jaldún ${ }^{82}$ (Lib. V, Cap. XIV), están alejadas de la caballerosidad de los nobles que encomendaban esas actividades, abominando el ejercicio directo de ellas, a agentes o a siervos. Sobre esto, basta reseñar el título de algunos capítulos de la Muqaddimah: «El carácter moral de los negociantes es inferior al de los nobles y los reyes» (Lib. V, Cap. XIV); « La moral delos comerciantes es inferior a la de los altos jefes, y sea leja de la de los hombres valerosos» (Lib. V, Cap. XV); juicios que hoy bastantes personas suscribirían.

Por otra parte, determinadas ideas de Ibn Jaldún, que considera, como Ibn Abdún ${ }^{83}$, que la agricultura es la base del desarrollo económico, sin llegar a todos sus aspectos, adelantan las de los fisiócratas dieciochistas, encabezados por Quesnay ${ }^{84}$, algunas de las

\footnotetext{
${ }^{78}$ Maurice GODELIER: Economía, Fetichismo y Religión en las sociedades primitivas; Madrid, 1978, p. 67.

${ }^{79}$ B. ABDÚN, ibídem, $\$ 91,92,95,105,117,149$ y 205, entre otros muchos.

${ }^{80}$ A. SMITH, ibídem, pp. 125, 241 ó 437.

${ }^{81}$ B. JALDÚN,ibídem, p. 677.

${ }^{82}$ B. JALDÚN,ibídem, p. 704.

${ }^{83} \mathrm{~B}$. ABDÚN, ibídem, (§3): «El príncipe debe prescribir que se dé el mayor impulso a la agricultura, la cual debe ser alentada».

${ }^{84}$ François QUESNAY: Maximes Générales du Gouvernement d'un royaume agricole, et notes sur ces maximes, en Physiocrates. Quesnay, Dupont de Nemours, Mercier de la Rivière, L'Abbé baudeau. Le Trosne, avec une introduction sur la doctrine des physiocrates, des commentaires et des notices historiques, par M. Eugène Daire, Paris, 1846.
} 
cuales siguen siendo asumidas en nuestros días. Para apreciarlo sólo es preciso recordar los títulos de algunas de las Máximas Generales del Gobierno de un Reino agrícola de Quesnay:

Máxima V.- Impuesto no destructivo.

Máxima VII.- Circulación completa (donde también se condena el atesoramiento).

Máxima XVIII.- Alto precio para los productos agrícolas y las mercancías.

Máxima XIX.- Los precios bajos son perjudiciales para el pueblo (donde también se hace ver que provocan el descenso de los salarios).

Máxima XX.- Desahogo para las clases bajas.

Máxima XXVII.- No ahorrar de los gastos públicos necesarios.

\section{Anexo: Impuestos legales en el Islam}

\begin{tabular}{|c|c|c|c|}
\hline Actividad & \begin{tabular}{|l|} 
Medio de \\
producción
\end{tabular} & Religión & Impuesto \\
\hline \multirow{4}{*}{ Agricultura } & \multirow[b]{2}{*}{ Tierras del Estado } & Musulmán & $\begin{array}{l}\text { Impuesto territorial } \\
\left(\mathrm{jar} / /{ }^{2}\right)\end{array}$ \\
\hline & & No musulmán & $\begin{array}{l}\text { Impuesto territorial } \\
\text { (jar//_) } \\
\text { Capitación (_izya) }\end{array}$ \\
\hline & \multirow[b]{2}{*}{ Tierras privadas } & Musulmán & Azaque (padaqa o zakāt) \\
\hline & & No musulmán & Capitación ( _izya) \\
\hline \multirow[b]{2}{*}{ Artesanía } & \multirow[b]{2}{*}{ Herramientas } & Musulmán & Azaque (padaqa o zakāt) \\
\hline & & No musulmán & Capitación ( _ izya) \\
\hline \multirow{3}{*}{ Comercio } & \multirow{3}{*}{ Dinero } & Musulmán & Diezmo ('ušr $r$ ), al 2,5\% \\
\hline & & No musulmán & Capitación (_izya), al 5\% \\
\hline & & $\begin{array}{l}\text { Extranjero no } \\
\text { musulmán }\end{array}$ & Diezmo ('ušr), al $10 \%$ \\
\hline
\end{tabular}




\section{Bibliografia:}

ABDÚN, Muhammad Ibn - Sevilla a comienzos del siglo XII. El Tratado de Ibn Abdún; versión de Évariste Lévi-Provençal y Emilio García Gómez. Madrid: Editorial Moneda y Crédito, 1948.XVI, 203 p.; 17 cm.

ARISTÓTELES - Metafísica; Madrid: Editorial Gredos, S.A., 1994.582 p.; 21 cm. ISBN 84.249.1666.2

ARISTÓTELES - La Política;4ª ed. Barcelona: Editorial Iberia, S.A., 1967. 306 p.; 19 $\mathrm{cm}$.

BIBLE -: Holy Bible Concordance. Red Letter Edition. Cleveland and New York: The World Publishing Company. 746 p., +226 p., +50 p., +124 p.; 14 ilus., 6 xer., 6 map.; 20 $\mathrm{cm}$.

BLAUG, Mark - Teoría económica en retrospección; $1^{\mathrm{a}}$ reimp. Madrid: Fondo de Cultura Económica, 1988. 856 p.; 22 cm. ISBN 8437502586.

CANTILLON, Richard - Ensayo sobre la naturaleza del comercio en general; $1^{\text {a }}$ reimp. México: Fondo de Cultura Económica, 1978. 234 p.; 23 cm. ISBN 968.16.0080.0.

CERVANTES, Miguel de - El Ingenioso Hidalgo Don Quijote de la Mancha; Madrid: Ediciones Castilla, S.A., 1966. CXI, 2h, 1986 p.; lam., grab.; 19cm.

CONSEJO SUPREMO DE CASTILLA: Consulta del Consejo Supremo de Castilla, en Obras del Licenciado Pedro Fernández Navarrete, en Biblioteca de Autores Españoles, Tomo 25, Madrid, M. Rivadeneyra, 1853. XXI, 560 p.; il.; 26 cm.

CORÁN - versión de Julio VERNET;2 ${ }^{a}$ ed. Barcelona: Plaza y Janés Editores, S.A., 1984. 588 p.; 18 cm. ISBN 84.01.37054-X. 
COSTAS COMESAÑA, Antón - "Industrialización y cuestión arancelaria en España. Reflexiones en torno al liberalismo de Laureano Figuerola", en Economía y economistas españoles, Tomo 4, pp. 459-482; Barcelona: Círculo de Lectores, 2000.767 p.: XL il; 22 cm. ISBN 84.226.7339.8.

ESTAPÉ RODRÍGUEZ, Fabián - "Ibn Jaldún: un economista del siglo XIV”, en Economía y Economistas Españoles, Tomo 2, pp. 75-97; Barcelona: Círculo de Lectores, 1999. 667 p.: LXVII, il; 22 cm. ISBN 84.226.7337.1.

FERNÁNDEZ NAVARRETE, Pedro - “Conservación de Monarquías”, en Obras de Don Diego de Saavedra Fajardo; y del Licenciado Pedro Fernandez Navarrete; Biblioteca de Autores Españoles, Tomo 25; Madrid: M. Rivadeneyra, 1853. XXI, 560 p.; il.; $26 \mathrm{~cm}$.

GARCÍA de CORTÁZAR, José Ángel - La época medieval, Tomo II de Historia de España Alfaguara;4a ed. Madrid: Alianza Editorial, S.A., 1977. 570 p.; 20 cm. ISBN 84.206.2998.7.

GIBB, Hamilton Alexander Rosskeen - "Fiscal Rescript of "Umar II", Arabica II, Leiden, 1955.

GODELIER, Maurice: Economía, Fetichismo y Religión en las sociedades primitivas; $2^{a}$ ed. Madrid: Siglo XXI de España Editores, S.A., 1978. 4h., 391 p.; 22 cm. ISBN 84.323.0163.9.

HARRIS, Marvin - Antropología cultural.1 ${ }^{a}$ ed. Madrid: Alianza Editorial, S.A., 1998. 622 p.; 18 cm. ISBN 84.206.3951.6.

JALDÚN, Abú Zayd Abd al-Rahmán ibn - Introducción a la historia universal (AlMuqaddimah). $1^{\text {a }}$ ed., $2^{\text {a }}$ reimp. México: Fondo de Cultura Económica, 1997. 1165 p.; $24 \mathrm{~cm}$. ISBN 968.16.2645.1.

JENOFONTE - Económico; versión bilingüe de Juan Gil. Madrid: Sociedad de Estudios y Publicaciones, 1967. 450 p.; 1h,: $24 \mathrm{~cm}$. 
KEYNES, John Maynard y HENDERSON, Hubert - “¿Puede hacerlo Lloyd George? Examen de la promesa”, en Ensayos de Persuasión. Barcelona: Ediciones Folio, S.A., vol. I, 1997. 2v, 448 p.; 21 cm, ISBN 84.413.0745.8.

KEYNES, John Maynard -"Medios para la prosperidad”, en Ensayos de Persuasión. Barcelona: Ediciones Folio, S.A., vol.II, 1997. 2v, 448 p.; 21 cm, ISBN 84.413.0745.8.

KEYNES, John Maynard -“Robert Malhus (1766-1835): The First of the Cambridge Economists”, en Essays and Sketches in Biography. New York: Meridian Books, 1956. $347 \mathrm{p}, ; 18 \mathrm{~cm}$.

MARX, Karl Heinrich y ENGELS, Friedrich - La Ideología Alemana.Montevideo: Ediciones Pueblos Unidos, S.A., 1968. 746 p.; 22 cm.

MONCADA, Sancho de - Restauración Política de España. Madrid: Instituto de Estudios Fiscales, 1974. 278 p.; $21 \mathrm{~cm}$.

MONTESQUIEU, Charles-Louis de Secondat, barón de la Brède y de Montesquieu Del Espíritu de las Leyes. Madrid: Editorial Tecnos, S.A., 1995. XLVII, 472 p.; ISBN 84.309.1136.7

ORTIZ, Luis - Memorial del contador Luis Ortiz a Felipe II.Edición de José Larraz, Madrid: Instituto de España, 1970. 150 p.; 25 cm.

PARDOS MARTÍNEZ, Eva - La incidencia de la protección arancelaria en los mercados españoles. Madrid: Estudios de Historia Económica, no 37, Banco de España, 1998, 159 p.; 24 cm, ISBN 84.7793.621.8.

QUESNAY, François - "Maximes Générales du Gouvernement d'un royaume agricole, et notes sur ces maximes" en Physiocrates/ Quesnay, Dupont de Nemours, Mercier de la Rivière, L'Abbé baudeau. Le Trosne, avec une introduction sur la doctrine des physiocrates, des commentaires et des notices historiques, par M. Eugène Daire.Paris: Librairie de Guillaumin, 1846. 2v, LXXXVIII-424 p.; 429-1027 p.; 25 cm. 
SMITH, Adam - Investigación sobre la naturaleza y causas de la riqueza de las naciones, $1^{\mathrm{a}}$ ed, $9^{\mathrm{a}}$ reimp. México: Fondo de Cultura Económica, 1994. LXXVI, 917 p.; $24 \mathrm{~cm}$. ISBM 968.16.0210.2.

VADILLO, José Manuel de - Discursos Económicos-Políticos y Sumario de la España Económica de los siglos XVI y XVII, corregidos y aumentados. Cádiz:Imprenta de D. D. Feros, 1844. 336 p.; $22 \mathrm{~cm}$.

\section{COMO CITAR ESTE ARTIGO}

\section{Referência electrónica:}

ESCARTIN, Eduardo, VELASCO, Francisco, GONZÁLEZ - ABRIL, Luis - “Impuestos moderados, según Ibn Jaldún”. Medievalista [Em linha]. №11, (Janeiro - Junho 2012). [Consultado dd.mm.aaaa]. Disponível em http://www2.fcsh.unl.pt/iem/medievalista/MEDIEVALISTA11ljaldun1104.html. ISSN 1646-740X.

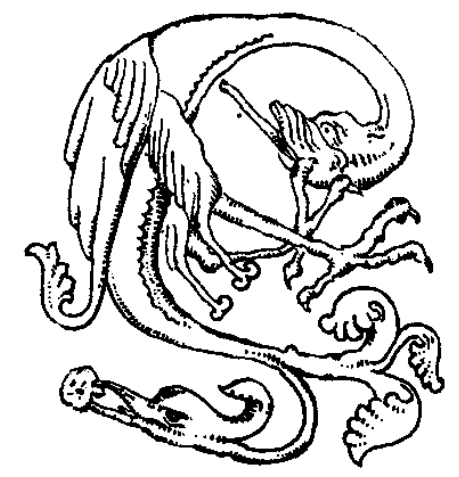

